\title{
Promoting Global Citizenship through an Information-Based Focus on United Nations International Events
}

\author{
Allen V. Del Carmen ${ }^{*}$ and Joevel A. Bartolome \\ Communication Department, College of Arts \& Sciences, University of St. La Salle, La Salle \\ Avenue, Bacolod 6100,Negros Occidental, Philippines
}

\begin{abstract}
Rapid advances in technology, information, and transportation have made true what was once just an idea. This was popularized by communication scholar Marshall McLuhan into a reality. These advances have consequently helped develop global citizenship education. With this development comes the realization that young people need not go out of their country to embrace global citizenship. What Journalism and Print Media students at the University of St. La Salle did to heighten their global citizenship education was to use mass and social media to promote selected international events of the United Nations under the project, "Connecting... Informing... We Are Citizens of the World". The feedback of the students show that such approach is an effective tool in making young people aware and be involved in the discussion and action for social justice and peace, which are requisites of global citizenship. This paper hopes to share with other S-L advocates, especially those in Communication programs that they can be vital channels in promoting global citizenship among their students as well as strategies they can use, and consequently, contribute to efforts toward the attainment of international peace, unity amid diversity and development.
\end{abstract}

Keywords: Global citizenship, United Nations Events, University of St. La Salle

\section{Introduction}

To speak about global citizenship in Service-Learning usually conjures of images of students leaving the comforts of familiar surroundings to immerse themselves for a week or more in some exotic places where they usually come face-to-face with the realities of want, poverty, health and other social problems. Advances in technology, information and communication and transportation have largely brought about a fresh notion of what global citizenship is all about since Canadian Communication scholar and philosopher Marshall McLuhan foretold the shrinking of the world into a global village and with it, the notion of the idea of global citizenship was heightened.

The rapid growth of communication technology was transforming what once was a wide, expansive world into a global village [1]. With the world shrinking into a village, people's awareness of each other, despite the distance, became greater. Thus, while before, global citizenship seemed abstract, today it has become tangible.

*Corresponding author: avdelc@gmail.com 


\section{Global citizenship defined}

But what is global citizenship? It is referred to as the knowledge and skills for social and environmental justice. It also covers the citizens' understanding of his or her responsibilities to others, to society and to the environment [2]. Global citizenship also allows the student to examine the meaning of democracy and citizenship from various perspectives as well as explore rights and obligations within their local realm as well as areas beyond their common domain. Furthermore, it enables them to reflect on concerns in their personal lives in relation to general; and global welfare and, at the same time, explore the relationship of this far-reaching notion of citizenship to the environment. The two researchers further advanced the idea that the students' understanding of issues from the local to the national and global level will result in the appreciation of a pluralistic society and constructive debates and enable them to access information from a wide range of reliable sources. According to [3], global citizenship education, on the other hand, allows us to see "the transformational nature" of student's learnings and experiences and gives educators a chance to incorporate reflective practice.

The United Kingdom-based Forum describes a global citizen as one who is aware of the wider world and has a sense of his own role as a citizen of the world, understands how the world works and is outraged by social injustices. He or she is also participative in a range of work in the community (global or local) and is willing to act to make the world an equitable and sustainable place.

To realize the globalcitizenship ideals, education is necessary. John Dewey, one of the moving spirits in Service-Learning was quoted as saying, "Education is not a preparation for life but it is life itself". He is attributed the idea that education for global citizenship deals with issues of global interdependence, diversity of identities and cultures, peace and conflict and inequities of power, resources and respect [4]. Global citizenship education also leadsto the students' critical and open-minded approaches in their discussion and possible resolution of issues. The students then practice various forms of citizenship skills, empowerment and sensitivity as well as wider participation in social action activities.

Global citizenship, while it has already been taught in classrooms in the past, has acquired an added meaning - that one can consciously become a global citizen and do hisorher share in promoting its goals of understanding and peace even while staying in their comfort zones. But this can be attained more realistically if it is grounded on what Dewey prescribed: on the personal experiences of the student and his or her community [2].

\subsection{UNESCO approach}

Providing more impetus to the thrust on global citizenship education is the United Nations Educational Scientific and Cultural Organization, which outlined its approach in the promotion of global citizenship of its Education Sector program for the 2014 to 2021 period. The organization underscores that it is guided by the Education 2030 Agenda and Framework for Action, particularly Sustainable Development Goal 4 on Education, which calls on nations to ensure that learners are provided with knowledge and skills to promote sustainable development through education that promotes, among others, human rights, gender equality, promotion of the culture of peace and non-violence, global citizenship and the appreciation of cultural diversityand of culture's contribution to sustainable development [5]. United Nations also emphasizes the role of educators in teaching people about the organization and its mission, making sure that their students find this learning as relevant when venturing into the professional world [6]. 


\subsection{GCE in Asia}

Asian universities have followed suit in implementing Global Citizenship Education in in their academic programs. Among the tertiary institutions that are frontrunners in embracing GCE is Lingnan University in Hong Kong which has been conducting the Global Citizenship Education/Cross Border Service-Learning Summer Institute, a cross-border experience of students from different Asian countries [7]. In Its "Walk Hand in Hand" volume, the 2013-14 S-L Annual Report, the university stated that as members of the global community, students and faculty can do their share in breaking the barriers for a society of amity and prosperity [8].

The Lingnan GCE/Cross Border SLSI, which was started in 2012 is an eight-week summer program that promotes global citizenship through Service-Learning. The program cites that while Global Citizenship is a program that has already been rooted in higher education, the prevailing internationalization and advocacy in civic engagement in higher education have further expanded civic education from national focus to a global one, thus broadening the concept of civic responsibility beyond national borders. The university has underscored that Service-Learning can be a way of global citizenship education and a powerful strategy in developing students as good citizens of the world.

\section{USLS communication students' S-L program}

The University of St. La Salle Communication S-L program was started in 2003 and has covered various disciplines mostly through information and education campaigns in keeping with the nature of the academic program of the Communication Department's past S-L activities - conducted in at least 15 communities in the province of Negros Occidental in central Philippines, included the following topics:
i). Youth, sex and marriage
ii). Livelihood productivity for farmers and fisherfolk
iii). Health education
iv). Voter education
v). Caring and sharing
vi). Calamity preparedness
vii). Climate change and environment issues information campaigns
viii). River conservation
ix). Literacy
x). Peace-building
xi). Community Relations Service and Action
xii). Senior Citizens' Rights
xiii). Sports Development
xiv). Campus Publication Management and Production

These activities were integrated either in Journalism, Community Communication or the Dialect Communication class [9].

\section{The global citizenship S-L program}

For the first time since 2003, a global perspective has been introduced for the ServiceLearning activityof Communication students. The instructor's occasional overseas travels have made an imprint on him that awareness of global social issues can shape young people's world view toward better understanding and social consciousness. With the students' present limitation on funds and time, overseas travel is not largely possible that 
thequestion was asked: "Why not bring the world to the students' experiences, considering that information technology has become handy, accessible and convenient?"

With their technological exposure, it has become easy for them to be aware of issues like climate change, waste segregation, social justice and global unemployment due to the replacement of human hands by machines. The instructor is cognizant of the fact that social issues are here-and-now and have intertwining effects regardless of the economic and industrial statuses of countries. What was equally significant was the observation that the activity can be meaningful to the students because the issues confront them and their communities.

In addition, many university administrators have started to implement global citizenship education as reflected in their vision, mission and goals [10]. At the University of St. La Salle, among the thrusts is the education of globally-competent and socially-aware citizens of the world". As anchored in its vision statement:"...the college aims to form students who are: secure in the richness of their Filipino cultural heritage but respectful of cultural diversity, making them true citizens of the world."

\subsection{Objectives}

The project, called "Connecting... Informing... We Are Citizens of the World", was therefore launched with the objectives for students to:

(i). Be aware of a universal social issue initiated by the United Nations for an increased consciousness of the value of global citizenship.

(ii). Establish partnerships with organizations that have functions related to the global issue.

(iii). Make use of their Communication and Journalism skills and knowledge to gather data, write, edit and circulate articles and other information to help promote a UN event.

(iv).Prepare an accomplishment report, evaluation and documentation of the project.

\subsection{Project mechanics}

To realize the objectives, students were grouped into pairs or three members with each group assigned to a pre-selected U.N. event toward the end of the semester-between October and December-which is the preliminary period of the semester. The tasks were defined:

(i). Familiarize with the event.

(ii). Find a partner agency (government, civil, or non-government) whose function is linked to the event.

(iii). Assist the partner-agency in its promotional activities for the event.

(iv). Write news and feature materials relevant to the event.

(v). Prepare promotional posters.

(vi). Use the social media and bulletin boards to promote public understanding of the event.

\section{The events}

The 13 events included in the Service-Learning activities represented an amalgam of social concerns. They were scheduled within the S-L module time frame. Theyfocused on human development, coping with emergency issues, poverty reduction and food sufficiency, justice health and inclusion. The UN activities were [11]: 
i). International Day for Disaster Reduction (October 13)

ii). International Day of Rural Women (October 15)

iii). World Food Day (October 16)

iv). International Day for the Eradication of Poverty (October 17)

v). World Cities Day (October 31)

vi). International Day to End Impunity for Crimes against Journalists (November 2)

vii). World Tsunami Awareness Day (November 5)

viii). World Diabetes Day (November 14)

ix). International Day for Tolerance (November 16)

x). World Day of Remembrance for Road Traffic Victims (November 20)

xi). Universal Children's Day (November 20)

xii). International Day for the Elimination of Violence against Women (November 25)

xiii). World AIDS Day (December 1)

For at least a month, the students undertook data-gathering activities related to their assigned events. The data gathering was done in government agencies and non-government organizations with functions pertinent to the event. They also scouted for possible people they can write about to humanize their stories. After at least two weeks, the materials were submitted for evaluation and editing prior to circulation.

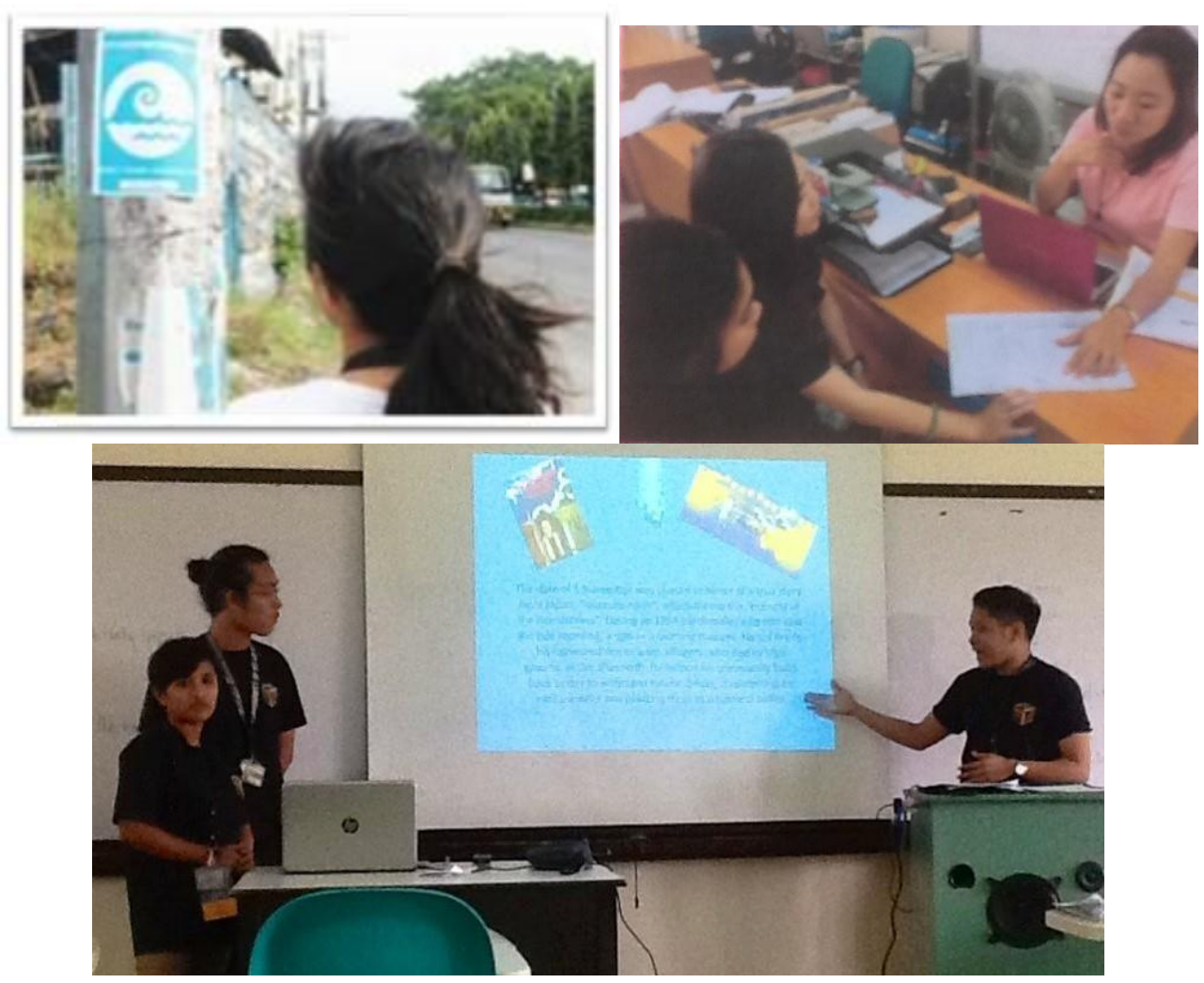

Fig. 1. Some of the activities the student engaged in — poster campaigns, interviews, and presentations. 


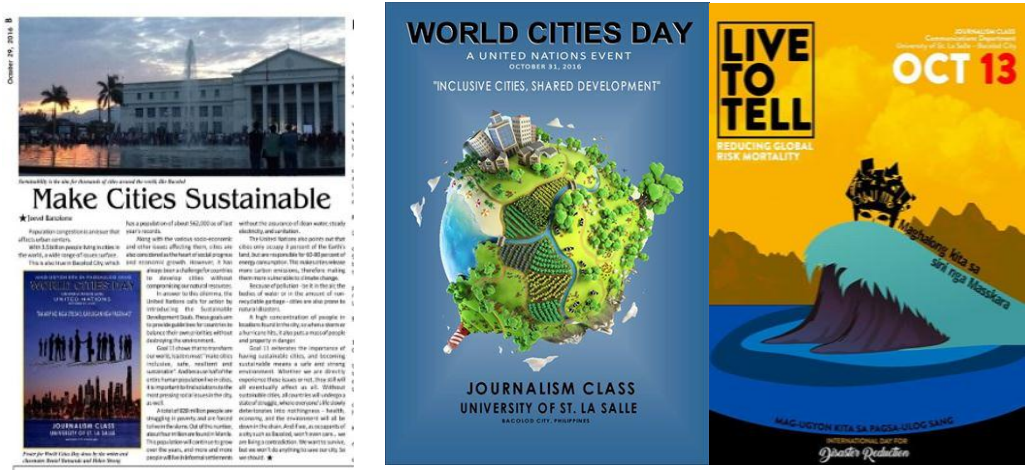

Fig. 2. Sample of students' outputs

Some of the written articles written by the students were published in a local newspaper and the posters were posted around announcement boards and different places in the city.

\section{Evaluation and findings}

An evaluation was conducted at the end of the semester to determine students' learning, their perceptions of the S-L activity and how it has impacted them. The evaluation was based on the four modes of community engagement developed by [12]. Butin's formula focuses on four dimensions oflearning: technical, cultural, political and anti-foundational.

The evaluation of the learning outcomes based on Oracion of the student must go beyond the usual confines of technical aspects, commonly on anchored on the acquisition of knowledge and skills. The Butin model showcases what has been contended that the evaluation of learning outcomes has to be anchored on the goal of community engagement: whether the service they will extend can enrich their knowledge and skills related to the students' academic discipline, can make them more sensitive and appreciative of people's ways of life and human differences, can propel their desire to assist in the pursuit for certain agenda that promote human well-being and better understanding of social institutions and can excite their ability to examine and critically question certain realities and practices that have been taken for granted and assumptions about certain phenomenon in life.

Thus, the model is viewed as one that can offer more systematic and broader ways of evaluating the performance of students that will ethically justify the investment they have in serving and learning with the community. The evaluation tool clustered a group of questions under each of the four Butin models. The questions related to technical learning covered personal motivation, opportunity for application of knowledge and enhancement of skills, including management-related functions, like planning, organizing and decision making as well as enrichment and expansion of their academic knowledge and skills through their public engagement. The cultural learning dimension was assessed through questions on their understanding of socio-cultural and global issues development of interpersonal and cross-cultural knowledge and skills, particularly on their level of empathy and sensitivity and appreciation of diversity and pluralism.

On the political aspect of learning, students were asked on the extent of their awareness of political and organizational procedures they were exposed to in the course of their preparations, coordination and implementation of the activity, their realizations related to citizenship and civic duty and enhancement of understanding of universal issues, like social justice and human rights [13]. 
The anti-foundational learning assessment focused on experiences that posed a challenge and redirected personal values, their exploration of horizons beyond their comfort zones and new realizations.In the evaluation, the students were asked to show their perc eptions on the four dimensions of learning using a scale of 5-with 1 as very low; 2 as low; 3 as average; 4 as high; and 5 as very high. Table 1 summarizes the ratings done by 37 students.

Table 1. Overall average of four types of learning.

\begin{tabular}{|l|l|}
\hline Type of learning & $\begin{array}{l}\text { Average } \\
\text { Rating by } 37 \text { students }\end{array}$ \\
\hline Technical learning & 4.20 \\
\hline Cultural learning & 4.14 \\
\hline Political learning & 4.12 \\
\hline Anti-foundational learning & 4.21 \\
\hline Average of four models & $\mathbf{4 . 1 7}$ \\
\hline
\end{tabular}

The tables below: 1a, 1b, 1c and 1d summarize the ratings done by the students on the technical, cultural, political and anti-foundational aspects of their learning experience.

Table 1.1. Summary of technical learning rating.

\begin{tabular}{|l|l|}
\hline Technical learning & $\begin{array}{l}\text { Average } \\
\text { Rating by 37 students }\end{array}$ \\
\hline Course-related skills and personal motivation & 4.20 \\
\hline $\begin{array}{l}\text { Improvement of journalistic and organizational and } \\
\text { management skills }\end{array}$ & 4.14 \\
\hline $\begin{array}{l}\text { Enrichment of Communication studies, Expansion of views } \\
\text { on media and social roles and career appreciation }\end{array}$ & 4.29 \\
\hline Technical learning Average & $\mathbf{4 . 2 0}$ \\
\hline
\end{tabular}

Table1.2. Summary of cultural learning rating.

\begin{tabular}{|l|l|}
\hline Cultural learning & $\begin{array}{l}\text { Average } \\
\text { Rating by 37 students }\end{array}$ \\
\hline Understanding of cultural issues & 4.23 \\
\hline Development of better inter-personal skills and empathy & 4.29 \\
\hline $\begin{array}{l}\text { Appreciation of cross-cultural concerns, diversity and } \\
\text { pluralism }\end{array}$ & 4.04 \\
\hline Cultural learning average & $\mathbf{4 . 1 4}$ \\
\hline
\end{tabular}

Table 1.3. Summary of political learning rating.

\begin{tabular}{|l|l|}
\hline Political learning & $\begin{array}{l}\text { Average } \\
\text { Rating by 37 students }\end{array}$ \\
\hline $\begin{array}{l}\text { Understanding of political structures, organizational } \\
\text { processes }\end{array}$ & 3.82 \\
\hline Expansion of civic consciousness and concern for others & 4.04 \\
\hline Enhancement of awareness on local and global citizenship & 4.50 \\
\hline Political learning average & $\mathbf{4 . 1 2}$ \\
\hline
\end{tabular}


Table 1.4. Summary of anti-foundational learning rating.

\begin{tabular}{|l|l|}
\hline Anti-foundational learning & $\begin{array}{l}\text { Average } \\
\text { Rating by } \mathbf{3 7} \text { students }\end{array}$ \\
\hline $\begin{array}{l}\text { Challenge to and re-alignment of personal values and } \\
\text { exploration beyond comfort zones }\end{array}$ & 4.14 \\
\hline $\begin{array}{l}\text { Acquisition of new learning } \\
\text { and adopt ways 'outside of my box' }\end{array}$ & 4.28 \\
\hline Realization of new beliefs and self-improvement & 4.21 \\
\hline Anti-foundational learning average & $\mathbf{4 . 2 1}$ \\
\hline
\end{tabular}

Overall, the students reflected an above-average learning based on the four dimensions of learning at 4.17 as shown in Table 1 . The model that showed the highest rating is antifoundational learning (4.21average shown in Table 1.4). Interestingly, similar studies conducted by the instructor earlier showed technical learning rating with the most favorable assessment and anti-foundational learning with a lower average. While the technical aspect of learning showed a relatively high rating (4.20 average shown in Table 1d), antifoundational insights edged it with its 4.21 average.

On the other extreme, political learning, while it also averaged above the 'high' rating, showed the lowest mark (4.12 in Table 1.3), slightly lower than the 4.14 average in cultural learning (Table 1.2). Among the different points considered, the enhancement of the understanding and awareness of local and national issues in the political aspect of learning had the highest mark at 4.50 (Table 1.3), which pulled up the average in that dimension after the lowest mark in all points was also noted in the same category of learning (Understanding of political structures and their processes at a 3.82 mark, the lowest in the entire rating done by the students).

\section{Students' feedback}

The evaluation included journal writing and small group discussions or reporting of experiences. Insights were categorized based on the four learning models. Table 2 shows the summary of the top three most common comments of the students.

Table 2.1. Summary of technical learning comments.

\begin{tabular}{|l|l|}
\hline Technical Learning & Frequency \\
\hline Data Gathering & 22 \\
\hline Interpersonal Skills & 14 \\
\hline Layout Skills & 9 \\
\hline
\end{tabular}

Table 2.2. Summary of political learning comments.

\begin{tabular}{|l|l|}
\hline Political Learning & Frequency \\
\hline System of Offices & 11 \\
\hline Public Concern & 9 \\
\hline Political Awareness & 7 \\
\hline
\end{tabular}

Table 2.3. Summary of cultural learning comments.

\begin{tabular}{|l|l|}
\hline Cultural Learning & Frequency \\
\hline Cultural Awareness & 20 \\
\hline Respect for other cultures & 6 \\
\hline Appreciation of diversity & 5 \\
\hline
\end{tabular}


Table 2.4. Summary of anti-foundational learning comments.

\begin{tabular}{|l|l|}
\hline Anti-foundational Learning & Frequency \\
\hline Concern/importance of topic & 16 \\
\hline Awareness of social issues & 9 \\
\hline Acceptance & 5 \\
\hline
\end{tabular}

\subsection{Technical Learning}

The following statements were among those articulated by the students in their evaluation:

(i). "My human relations and communication skills were greatly enhanced."

(ii). "I realized that I need to improve my data-gathering skills to come up with a comprehensive report."

(iii). "I maximized my creativity as I was in-charge of designing and producing our group's poster."

(iv). "Media management skills were put into good use - from planning, coordination, time management to decision making - and further improved."

(v). "I learned how to use our acquired skills and knowledge for information dissemination."

\subsection{Cultural learning}

(i). "I have come to appreciate diversity, open-mindedness and empathy for others. It is important that we exercise tolerance as a way of respecting others who have different beliefs."

(ii). "I have realized that people who come from a different culture have their own ways of doing things and that we should not judge them by our own standards."

(iii). "I have relearned the value of respect for other cultures and beliefs.

(iv). "I have come to value people s uniqueness and embrace other cultures."

\subsection{Political learning}

(i). "I became aware of public issues and have become more politically aware. I was also made more conscious of my duties a local and global citizen."

(ii). "I understand better now the workings in government and of officials."

(iii). "I have learned that it is importantfor us to make a stand on issues and have our voices heard so that others understand these issues and make a choice so that they can act accordingly."

(iv). "As citizens of the world, it made me realize that our rights are important and we should fight for them."

\subsection{Anti-foundational learning}

(i). "I should give more attention to the things I usedto ignore, like theobservance of international events, which have important bearings in our daily lives."

(ii). "We should be active in initiating and supporting advocacies for they help improve the quality of life of the marginalized and the disadvantaged."

(iii). "I am now more aware of international events and the significance of these events in international and domestic affairs."

(iv). "I felt responsible for having taken action to spread awareness to my fellow human beings about important issue..." 
(v). We should be more sensitive to the plight of others instead of being self-focused. To me this is what global citizenship is all about."

\subsection{Related outcomes}

Developments related to the students' activities took place after partner organizations were made aware of the global events. It is noted that not all concerned agencies approached by the students were aware of the existence of the events:

(i). A city councilor is sponsoring a resolution seeking the formal celebration of World Cities Day next year in the locality.

(ii). The Disaster Risk and Reduction Management Office of the Provincial Government advised its offices in towns and cities to conduct their own activities in celebration of International Day for Disaster Reduction.

(iii). A local government agency said now that it is aware of the international observance, it will draw up plans for a celebration starting next year.

(iv). The Journalism Class forwarded details of the class activity to the United Nations representative in the Philippines.

\section{Conclusion}

To measure their general perception, students were asked two questions to determine the overall effect of the activity on their education. They were asked how they viewed the activity and its impact on their lives. Thirty-five of the 37 students indicated that the activity meant "more than just a class requirement". On their rating of the impact of the S-L global citizenship activity on their lives, the class average was a high 4.62 average. The students, while promoting their assigned UN event through writing and creating poster layouts, enhanced their technical, cultural, political, and anti-foundational skills and learnings. These aren't their only outcomes, since some event went beyond the regular trimedia campaign. To broaden the promotion of the event, the students also contacted and collaborated with government agencies to bring these events into the city - examples of which are the local government unit and the DRRM office of the province - thus, bringing the goals of the UN closer to the people of Bacolod.

\section{References}

1. University of Illinois. Do we live in a global village? [Online] from http://www.library.illinois.edu/village/globalnews/mod1/pg1.htm (2009). [Accessed on 27 April 2017].

2. J. Andrzejewski, J. Alessio, Education for global citizenship and social responsibility. [Online] from http://citeseerx.ist.psu.edu/viewdoc/download?doi=10.1.1.524.3056\&rep $=$ rep1\&type $=p$ df (1998). [Accessed on 25 April 2017]

3. M. Brigham. Journal of Global Citizenship \& Equity Education, 1,1:15-43(2011). http://journals.sfu.ca/jgcee/index.php/jgcee/article/view/27

4. IDEAS. Ideasfor global citizenship. [Online] from http://www.ideasforum.org.uk/education (n.d.). [Accessed on 27 April 2017].

5. UNESCO. Global citizenship education. [Online] from http://en.unesco.org/gced/approach (2014). [Accessed on 25 April 2017]

6. UN Chronicle. Magazine of the United Nations, L,4(2013). https://unchronicle.un.org/article/teaching-un-through-experiential-education 
7. E.H. Hing, C.P. Yee, A.C. On. Teaching and learning global citizenship through service-learning: The sucess story of cross-border Service-Learning Summer Insititute, Lingnan University, Hong Kong. [Online] from http://commons.ln.edu.hk/cgi/viewcontent.cgi?article $=1073 \&$ context $=$ osl_conference (2013). [Accessed on 27 April 2017]

8. Lingnan University. Walk hand in hand - service-learning annual report 2014. Hongkong: Lingnan University (2015). http://commons.ln.edu.hk/osl_annualreport/8/

9. A. Del Carmen. Environmental information \& education campaign in a pilot creek community: A civic engagement and learning experience of communication students of the University of St. La Salle, Bacolod City, Philippines. Presented at the 4th AsiaPacific Regional Conference on Service-Learning (Lingnan University, Hong Kong, 2013). http://commons.ln.edu.hk/osl_conference/4th/breakout_1d/2/

10. S. Jorgenson, L. Shultz. Global citizen citizenship education (gce) in post-secondary institutions: what is protected and what is hidden under the umbrella of gce?, Journal of Global Citizenship \& Equity Education, 2,1(2012). [Online] from http://journals.sfu.ca/jgcee/index.php/jgcee/article/viewArticle/52/26 (2012). [Accessed on 25 April 2017]

11. United Nations. International days. [Online] from http://www.un.org/en/sections/observances/international-days/ (n.d.). [Accessed on 27 April 2017]

12. D.W. Butin. Change. 39,6:34-37(2007). https://www.jstor.org/stable/40178270?seq=1\#page_scan_tab_contents

13. L. Davies, Journal Educational Review, 58,1:5-25(2006). https://www.tandfonline.com/doi/abs/10.1080/00131910500352523 